\section{BRAZIULIAN JOURNAL \\ OF MEDICAL AND BIOLOGICAL RESHARCH}

www.bjournal.com.br
ISSN 0100-879X

Volume 42 (10) 870-992 October 2009

BIOMEDICAL SCIENCES

AND

CLINICAL INVESTIGATION

Braz J Med Biol Res, October 2009, Volume 42(10) 954-957

Evidence that blood pressure remains under the control of arterial baroreceptors in renal hypertensive rats

A.S. Trindade Jr., E.D. Moreira, G.J.J. Silva and E.M. Krieger

The Brazilian Journal of Medical and Biological Research is partially financed by
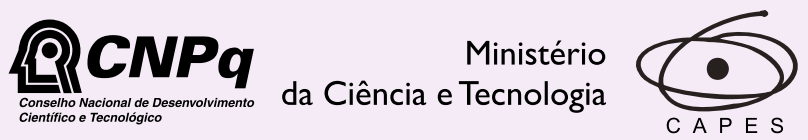

Ministério da Educação
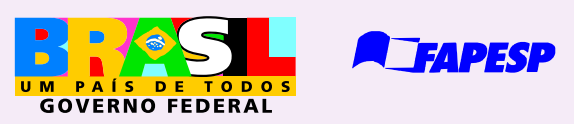

Institutional Sponsors 


\title{
Evidence that blood pressure remains under the control of arterial baroreceptors in renal hypertensive rats
}

\author{
A.S. Trindade Jr. ${ }^{1}$, E.D. Moreira ${ }^{2}$, G.J.J. Silva² and E.M. Krieger ${ }^{2}$ \\ 1Departamento de Ciências Biológicas, Faculdade de Odontologia de Bauru, \\ Universidade de São Paulo, Bauru, SP, Brasil \\ ${ }^{2}$ Unidade de Hipertensão, Instituto do Coração, Faculdade de Medicina, \\ Universidade de São Paulo, São Paulo, SP, Brasil
}

\begin{abstract}
The purpose of the present study was to determine the range of the influence of the baroreflex on blood pressure in chronic renal hypertensive rats. Supramaximal electrical stimulation of the aortic depressor nerve and section of the baroreceptor nerves (sinoaortic denervation) were used to obtain a global analysis of the baroreceptor-sympathetic reflex in normotensive control and in chronic (2 months) 1-kidney, 1-clip hypertensive rats. The fall in blood pressure produced by electrical baroreceptor stimulation was greater in renal hypertensive rats than in normotensive controls (right nerve: $-47 \pm 8$ vs $-23 \pm 4 \mathrm{mmHg}$; left nerve: -51 \pm 7 vs $-30 \pm 4 \mathrm{mmHg}$; and both right and left nerves: $-50 \pm 8$ vs $-30 \pm 4 \mathrm{mmHg} ; \mathrm{P}<0.05)$. Furthermore, the increase in blood pressure level produced by baroreceptor denervation in chronic renal hypertensive rats was similar to that observed in control animals $2-5 \mathrm{~h}$ (control: $163 \pm 5$ vs $121 \pm 1 \mathrm{mmHg}$; $1 \mathrm{~K}-1 \mathrm{C}$ : $203 \pm 7$ vs $170 \pm 5 \mathrm{mmHg} ; \mathrm{P}<0.05$ ) and $24 \mathrm{~h}$ (control: $149 \pm 3$ vs 121 $\pm 1 \mathrm{mmHg}$; $1 \mathrm{~K}-1 \mathrm{C}$ : $198 \pm 8$ vs $170 \pm 5 \mathrm{mmHg}$; $\mathrm{P}<0.05)$ after sinoaortic denervation. Taken together, these data indicate that the central and peripheral components of the baroreflex are acting efficiently at higher arterial pressure in renal hypertensive rats when the aortic nerve is maximally stimulated or the activity is abolished.
\end{abstract}

Key words: Arterial baroreceptor; Renal hypertension; Sinoaortic denervation; Aortic depressor nerve; Electrical stimulation

\section{Introduction}

Studies conducted over the last 40 years to treat resistant hypertension in humans by electrical stimulation of the sinus area (for references, see 1) have emphasized that a better understanding is needed of the alterations produced by hypertension on the afferent (baroreceptors), central and efferent (vagal and sympathetic) components of the baroreflex. Resetting of the baroreceptors to act at the hypertensive level, but with reduced gain sensitivity, has been well documented in animal models (2-6). However, less information is available about the functional activity of the central and peripheral components of the baroreflex in hypertension. This will influence the role of the baroreceptors in the long-term control of blood pressure (7-9).

Recent studies on conscious spontaneously hypertensive rats $(10,11)$ demonstrated that when electrical stimulation of the aortic depressor nerve bypassed the impaired sensitivity of the baroreceptors on the arterial wall, the inhibition of the sympathetic system by the barorecep- tors was well preserved. We have shown that in chronic renal hypertensive rats (12) the baroreceptors reset to hypertensive levels and still maintain the inhibitory activity on the splanchnic nerve in an apparently normal fashion. Using the same model, in the present study, we analyzed the blood pressure range below and above the basal level, that is under the control of the baroreflex when hypertensive rats are submitted to maximal baroreceptor stimulation and sinoaortic denervation.

\section{Material and Methods}

Adult (12 weeks old) male and female Wistar rats (180-250 g) randomized into control, and renovascular hypertension groups were studied. They were kept under a 12-h light/dark cycle at a controlled ambient temperature $\left(\sim 22^{\circ} \mathrm{C}\right)$. Standard laboratory diet and water were available ad libitum. The experimental procedures were conducted in

Correspondence: E.M. Krieger, Unidade de Hipertensão, InCor, Av. Dr. Enéas C. Aguiar, 44, 2oandar, Bloco II, 05403-000 São Paulo, SP, Brasil. Fax: +55-11-3069-5048. E-mail: edkrieger@incor.usp.br

Received March 12, 2009. Accepted September 4, 2009. Available online September 28, 2009. 
accordance with the guidelines for care and use of laboratory animals of the University of São Paulo, Brazil.

\section{Electrical stimulation}

Electrical stimulation $(2 \mathrm{~ms}, 100 \mathrm{~Hz}, 5$ volts over a period of $15 \mathrm{~s}$ ) of both right and left aortic depressor nerve was standardized according to a previous study (12) in anesthetized Wistar rats. A catheter was implanted into the aorta via the right femoral artery (PE-10) for direct blood pressure measurement. Anesthesia with chloralose $(50 \mathrm{mg} / \mathrm{kg})$ plus urethane $(500 \mathrm{mg} / \mathrm{kg})$ was chosen after a preliminary test with urethane alone. The rats received methylatropine $(2 \mathrm{mg} / \mathrm{kg})$ to abolish the bradycardic response, with the hypotensive response being maintained due to sympathoinhibition (13).

\section{Sinoaortic denervation}

Sinoaortic denervation (SAD) was performed under light anesthesia according to a method standardized in our laboratory (14). Briefly, the aortic depressor fibers, either traveling with the sympathetic nerve or as an isolated aortic nerve, were cut. The communicating branch of the aortic fibers was also sectioned. The third contingent of aortic baroreceptor fibers traveling with the inferior laryngeal nerve was interrupted by resection of the superior laryngeal nerve after the carotid bifurcations were exposed extensively for carotid stripping. In addition, the sinus nerve, all carotid branches, and the carotid body were also sectioned. All procedures were completed within 20-30 min and the rats were allowed to recover over a period of $2 \mathrm{~h}$. A previous study (15) showed that the increase in pressure remained constant within the first $5 \mathrm{~h}$ after SAD. Blood pressure was directly and continuously recorded through the femoral artery of conscious SAD rats for $2 \mathrm{~h}$ (from 2-5 h after denervation) and for 1 $\mathrm{h}$ after $24 \mathrm{~h}$ of SAD.

\section{$1 \mathrm{~K}-1 \mathrm{C}$ renal hypertensive rats}

Chronic (2 months) 1-kidney, 1-clip (1K-1C) renal hypertensive rats were used (16). Briefly, an u-shaped silver clip (lumen diameter of $0.35-0.40 \mathrm{~mm}$ ) was implanted around the left renal artery, following by nephrectomy of the right kidney. Surgical mortality was below 5\%, and 2-month mortality rate was $15 \%$. Tail plethysmographic pressure was recorded in $1 \mathrm{~K}-1 \mathrm{C}$ rats once a week to confirm that a stable hypertensive level had been reached.

\section{Statistical analysis}

Data are reported as means \pm SEM or SD (to analyze variability). Two-way analysis of variance (ANOVA), followed by the Bonferroni post hoc test, was used to compare the means, and the level of significance was set at $P<0.05$.

\section{Results}

Figure 1 illustrates typical tracings showing the pulsatile and mean blood pressure (panel A) of a normotensive (control) rat and of a chronic $1 \mathrm{~K}-1 \mathrm{C}$ rat before and after electrical stimulation of the right, left, or both aortic depressor nerves under anesthesia. The fall in blood pressure produced by supramaximal stimulation, when sinoaortic baroreceptor fibers were intact, was significantly greater
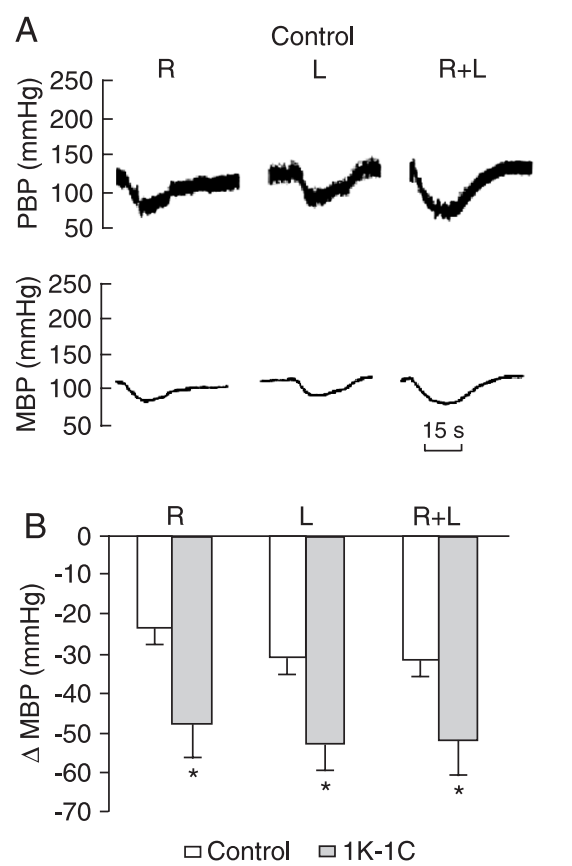

www.bjournal.com.br
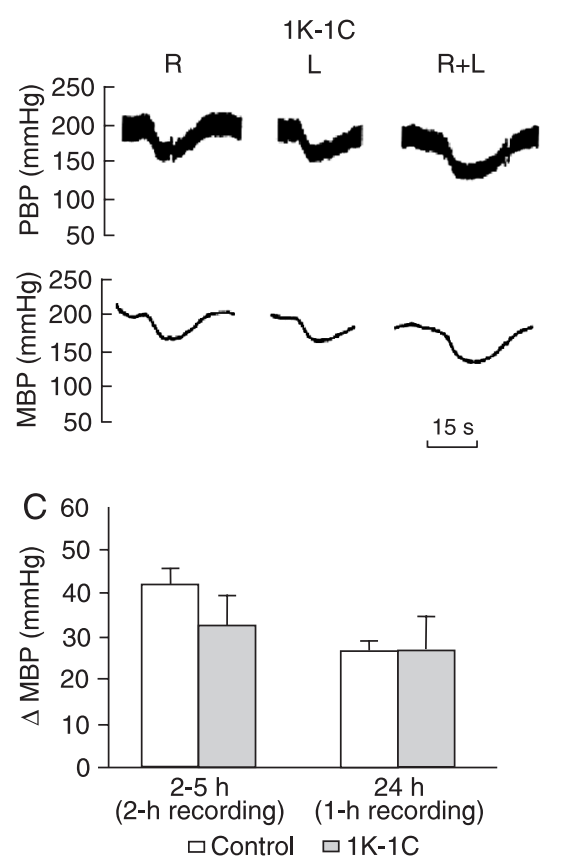

Figure 1. Typical tracings (panel A) from an anesthetized normotensive (control) rat and a chronic 1-kidney/1-clip renal hypertensive $(1 \mathrm{~K}-1 \mathrm{C})$ rat showing pulsatile (PBP) and mean blood pressure (MBP) before and after electrical stimulation of the aortic depressor nerve. Panel B, MBP reductions after electrical stimulation of the right $(R)$, left $(L)$, and both right and left $(\mathrm{R}+\mathrm{L})$ aortic depressor nerves in control $(\mathrm{N}=10)$ and $1 \mathrm{~K}-1 \mathrm{C}(\mathrm{N}$ $=7$ ) rats. Panel $C$, MBP increase $2-5 \mathrm{~h}$ and $24 \mathrm{~h}$ after sinoaortic denervation in conscious control $(\mathrm{N}=8)$ and $1 \mathrm{~K}-1 \mathrm{C}(\mathrm{N}$ $=9)$ rats. ${ }^{*} P \leq 0.05$ compared to control (two-way ANOVA). 
in renal hypertensive rats $(\mathrm{N}=7)$ than in the normotensive rats $(N=10$; Figure 1 , panels $A$ and $B)$. The right and left aortic nerves exhibited the same responses in chronic hypertensive and normotensive control rats. Similar results were obtained when the stimulation was performed after sinoaortic denervation (data not shown). Moreover, baroreceptor afferent stimulation was carried out in two different conditions (artificial controlled and uncontrolled respiration) to avoid the influence of respiratory movements on the blood pressure responses, and the results were essentially similar (data not shown).

Continuous analysis of blood pressure showed an increase in mean level 2-5 h (control: $163 \pm 5$ vs $121 \pm 1$ $\mathrm{mmHg}$; 1K-1C: $203 \pm 7$ vs $170 \pm 5 \mathrm{mmHg}$; $\mathrm{P}<0.05)$ and $24 \mathrm{~h}$ (control: $149 \pm 3$ vs $121 \pm 1 \mathrm{mmHg}$; $1 \mathrm{~K}-1 \mathrm{C}$ : $198 \pm 8$ vs $170 \pm 5 \mathrm{mmHg} ; \mathrm{P}<0.05)$ after sinoaortic denervation. The increases in blood pressure produced by SAD within the first $5 \mathrm{~h}$ after anesthesia and surgical trauma were slightly higher than those observed after $24 \mathrm{~h}$, suggesting that these factors had no important effect on the pressure responses. In addition, blood pressure lability was also increased 2-5 h (control: $27 \pm 13$ vs $8 \pm 2 \mathrm{mmHg}$; $1 \mathrm{~K}-1 \mathrm{C}$ : $19 \pm 10$ vs $10 \pm 5 \mathrm{mmHg} ; \mathrm{P}<0.05)$ and $24 \mathrm{~h}$ (control: 19 \pm 9 vs $8 \pm 2 \mathrm{mmHg} ; 1 \mathrm{~K}-1 \mathrm{C}: 15 \pm 5$ vs $10 \pm 5 \mathrm{mmHg} ; \mathrm{P}<$ $0.05)$ after sinoaortic denervation. Additional increases in blood pressure produced by baroreceptor denervation in the rats with chronic renal hypertension $(\mathrm{N}=9,1 \mathrm{~K}-1 \mathrm{C})$ were not significantly different from those observed in control $(\mathrm{N}$ =8) rats (Figure 1, panel C).

\section{Discussion}

The major finding of the present study was that the baroreceptors of chronic renal hypertensive rats still can control a wide range of blood pressure fluctuations, both above and below the basal level, also controlling blood pressure lability. Moreover, the decrease in blood pressure produced by electrical stimulation of the baroreceptors was greater than that observed in normotensive rats, suggesting an overacting sympathetic system in the hypertensive rats. Figure 2 shows a schematic illustration of the blood pressure range under the control of baroreflex when the normotensive and hypertensive rats were submitted to maximal baroreceptor stimulation and sinoaortic denervation. This is not surprising since the resetting of the baroreceptors in chronic hypertension is accompanied by reduced gain sensitivity (2-6), thus reducing the inhibitory capacity effect of the baroreceptors on the sympathetic system. It should be emphasized that electrical stimulation of the aortic nerve overcomes the decreased baroreceptor sensitivity. Another explanation of the increased sympathetic activity is the central adaptation or resetting of the baroreflex represented by the alteration in the coupling of the afferent baroreceptors to the efferent sympathetic and

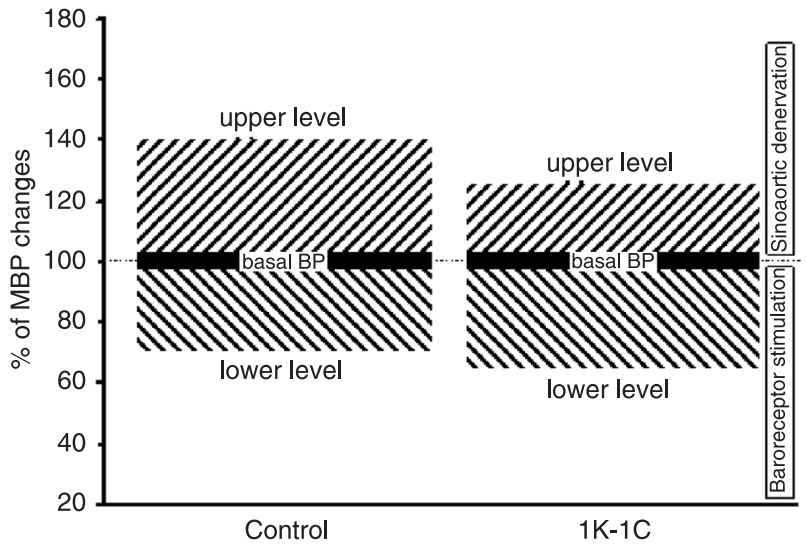

Figure 2. Schematic representation of the range of baroreceptor control of blood pressure (\% of MBP changes) using data from Figure 1. The upper level was obtained from a conscious rat in response to sinoaortic denervation and the lower level from an anesthetized rat by electrical stimulation of the aortic nerve. Left, normotensive control rat; right, chronic 1-kidney/1-clip renal hypertensive $(1 \mathrm{~K}-1 \mathrm{C})$ rat.

parasympathetic systems $(3,4,17,18)$.

More recently, the consensus concerning the role of the baroreflex in the long-term control of arterial pressure has been revised $(7-9,19)$ with the suggestion that baroreceptor resetting may not be complete in chronic hypertension. However, the decreased gain in sensitivity that always accompanied the complete resetting associated with central resetting in chronic hypertension could explain why the baroreflex is unable to attenuate the sympathetic activity. Therefore, the incomplete resetting should be more appropriately related to the activity of the baroreflex as a whole (afferent, central and efferent sites), even when the resetting of the baroreceptor (afferent) is complete. According to Dickinson (17), "it is unlikely that there are any peripheral arterial baroreceptor systems which will not eventually reset, given sufficient time".

Finally, it should be remembered that, according to Folkow (20), the increased wall to lumen ratio (hypertrophy) of the resistance vessels in hypertension is more sensitive to the sympathetic stimulus and that more marked blood pressure responses should be expected when the sympathetic system is activated or deactivated. This probably explains why the acute administration of hypotensive drugs and the depressor nerve stimulation usually produce a greater fall in pressure when blood pressure is decreased.

\section{Acknowledgments}

We gratefully acknowledge the financial support of FAPESP and Fundação Zerbini. 


\section{References}

1. Mohaupt MG, Schmidli J, Luft FC. Management of uncontrollable hypertension with a carotid sinus stimulation device. Hypertension 2007; 50: 825-828.

2. Andresen MC, Yang M. Arterial baroreceptor resetting: contributions of chronic and acute processes. Clin Exp Pharmacol Physiol Suppl 1989; 15: 19-30.

3. Chapleau MW, Hajduczok G, Abboud FM. Peripheral and central mechanisms of baroreflex resetting. Clin Exp Pharmacol Physiol Suppl 1989; 15: 31-43.

4. Korner PI. Baroreceptor resetting and other determinants of baroreflex properties in hypertension. Clin Exp Pharmacol Physiol Suppl 1989; 15: 45-64.

5. Moreira ED, Ida F, Oliveira VL, Krieger EM. Early depression of the baroreceptor sensitivity during onset of hypertension. Hypertension 1992; 19: II-198-II-201.

6. Sleight P. Arterial baroreflexes can determine long-term blood pressure. Baroreceptors and hypertension: time for a re-think? Exp Physiol 2004; 89: 337-341.

7. Brooks VL, Sved AF. Pressure to change? Re-evaluating the role of baroreceptors in the long-term control of arterial pressure. Am J Physiol Regul Integr Comp Physiol 2005; 288: R815-R818.

8. Malpas SC. What sets the long-term level of sympathetic nerve activity: is there a role for arterial baroreceptors? Am J Physiol Regul Integr Comp Physiol 2004; 286: R1-R12.

9. Thrasher TN. Baroreceptors and the long-term control of blood pressure. Exp Physiol 2004; 89: 331-335.

10. Salgado HC, Barale AR, Castania JA, Machado BH, Chapleau MW, Fazan R Jr. Baroreflex responses to electrical stimulation of aortic depressor nerve in conscious SHR. Am J Physiol Heart Circ Physiol 2007; 292: H593-H600.
11. Durand MT, Fazan R Jr, Salgado MC, Salgado HC. Acute and chronic electrical activation of baroreceptor afferents in awake and anesthetized subjects. Braz J Med Biol Res 2009; 42: 53-60.

12. Krieger EM, Marseillan RF. Neural control in experimental renal hypertension. The role of baroreceptor and splanchnic fibers. Acta Physiol Lat Am 1966; 16: 343-352.

13. De Paula PM, Castania JA, Bonagamba LG, Salgado HC, Machado BH. Hemodynamic responses to electrical stimulation of the aortic depressor nerve in awake rats. Am J Physiol 1999; 277: R31-R38.

14. Krieger EM. Neurogenic hypertension in the rat. Circ Res 1964; 15: 511-521.

15. Krieger EM. The acute phase of neurogenic hypertension in the rat. Experientia 1970; 26: 628-629.

16. Schaffenburg CA. Device to control constriction of main renal artery for production of hypertension in small animals. Proc Soc Exp Biol Med 1959; 101: 676-677.

17. Dickinson CJ. Re: baroreceptors and the long-term control of blood pressure. Exp Physiol 2004; 89: 335-337.

18. Schreihofer AM, Ito S, Sved AF. Brain stem control of arterial pressure in chronic arterial baroreceptor-denervated rats. Am J Physiol Regul Integr Comp Physiol 2005; 289: R1746R1755.

19. Lohmeier TE, Lohmeier JR, Warren S, May PJ, Cunningham JT. Sustained activation of the central baroreceptor pathway in angiotensin hypertension. Hypertension 2002; 39: 550556.

20. Folkow B. Physiological aspects of primary hypertension. Physiol Rev 1982; 62: 347-504. 